\title{
ANALISIS DISTRIBUSI PENDAPATAN PADA USAHA IKAN NILA DI KECAMATAN SEGINIM, KABUPATEN BENGKULU SELATAN
}

\author{
Income Distribution Analysis of Tilapia Business in Seginim District, \\ South Bengkulu
}

Sriyoto, Reswita, dan Hardianto

Jurusan Sosial Ekonomi Pertanian Fakultas Pertanian Universitas Bengkulu

\begin{abstract}
Indonesia has a very rich fisheries resources and potential both in the fresh waters, the coast, and sea water covering land diversity of fish and fisheries. One type of fresh water fish that has been cultivated is Tilapia. In Indonesia, Tilapia is economically valuable fish which has been cultivated by fish farmers in various areas. Seginim district in Southern Bengkulu is one region in Sumatera that produces cultivator of Tilapia. The objectives of this study were to 1) know the income of Tilapia farmers and 2) know the income distribution in the business of Tilapia. The determination of respondents in this research was taken from the business of Tilapia. The respondents were determined by using census method and the number of respondents were 54 people. The primary data was taken directly from the respondents by using interview method to the enterpreneuss, and by using questionaires. The secondary data was obtain from the Seginim district office and related literature. the analysis instrument used was the income analysis and income distribution of the business of Tilapia. The results of the study showed that the income of the business of Tilapia in Seginim district of Southern Bengkulu was Rp22,204,786.27 per farm per season. The part obtained by fish feed businessman was 45.17 percent; by fish seed businessman was 29.25 percent; by fish farmers was 19.22 percent; and by farm workers was 6.36 percent.
\end{abstract}

Keywords : Tilapia fish farmers, Income, Income distribution

\section{PENDAHULUAN}

Indonesia merupakan negara yang memiliki kekayaan sumber daya perikanan baik di wilayah perairan tawar (darat), pantai maupun perairan laut. Potensi sumber daya perikanan di perairan tawar meliputi keanekaragaman jenis ikan dan lahan perikanan. Di perairan tawar terdapat begitu banyak jenis ikan salah satunya adalah ikan nila dan tergolong ikan yang bernilai ekonomis.

Provinsi Bengkulu dari beberapa wilayah penghasil ikan nila di Sumatera, berada pada urutan yang kelima. Pada tahun 2008 produksi ikan nila sebesar 
5.738 ton, pada tahun 2009 menjadi 7.134 ton dan pada tahun 2012 produksi mencapai sebesar 11.271 ton. Kabupaten Bengkulu Selatan merupakan pemasok ikan nila yang cukup besar bagi Provinsi Bengkulu. Berdasarkan data Dinas Perikanan dan Kelautan Kabupaten Bengkulu Selatan (2013), produksi ikan nila di Kabupaten Bengkulu Selatan mencapai 2.941,15 ton. Produksi ikan nila yang dihasilkan dari Kecamatan Seginim dipasarkan di daerah Seginim, juga dipasarkan ke wilayah Merpes, Pagaralam, dan Palembang. Permintaan ikan nila dari Palembang cukup tinggi, sehingga di Kecamatan Seginim budidaya ikan nila akan bertambah. Hal ini membuktikan bahwa peluan usaha budidaya ikan nila cukup menjanjikan.

Meningkatnya permintaan ikan nila, maka petani ikan dituntut untuk memaksimalkan produksi dan kualitas, sehingga harga ikan yang diterima petani akan lebih baik dan pada gilirannya pendapatan petani ikan nila meningkat. Dari pendapatan petani ikan nila tersebut akan dapat diketahui besarnya distribusi pendapatan dilihat dari besarnya bagian yang diterima oleh pemilik faktor produksi (petani ikan, buruh tani, dan pengusaha sarana produksi).

Berangkat dari penjelasan di atas, penelitian ini bertujuan untuk mengetahui besarnya pendapatan dan distribusi pendapatan pada usaha pembesaran ikan nila di Kecamatan Seginim Kabupaten Bengkulu Selatan.

\section{METODE PENELITIAN}

Penelitian ini dilakukan di Kecamatan Seginim, Kabupaten Bemgkulu Selatan. Lokasi penelitian ditetapkan secara sengaja (purposive), dengan pertimbangan lokasi tersebut merupakan salah satu kecamatan yang mengusahakan pembesaran ikan nila dengan produktivitas cukup besar di Kabupaten Bengkulu Selatan. Penelitian dilaksanakan pada bulan Desember 2013.

Data yang dikumpulkan ada dua jenis, yaitu data primer dan sekunder. Data primer diperoleh melalui wawancara langsung kepada pengusaha pembesaran ikan nila, kemudian data tersebut diolah untuk kepentingan analisa lebih lanjut. Data sekunder yaitu data yang diperoleh dari literatur (buku, jurnal maupun hasil penelitian terdahulu) yang digunakan sebagai data penunjang dalam penelitian. Di samping itu data sekunder juga dapat diperoleh dari berbagai instansi pemerintah yang ada kegiatannya dengan penelitian.

Metode penentuan sampel dalam penelitian ini dilakukan dengan menggunakan metode sensus, yakni melibatkan seluruh populasi sebagai sampel. Sampel yang menjadi target penelitian adalah pengusaha pembesaran ikan nila dengan kolam permanen di Kecamatan Seginim, Kabupaten Bengkulu Selatan yaitu sebanyak 54 petani ikan nila. 


\section{Metode Analisis Data}

Analisis data yang digunakan dalam penelitian ini terdiri dari analisis kualitatif dan kuantitatif. Analisis kualitatif dilakukan melalui pendekatan deskriptif. Analisis deskriptif yaitu mencermati fenomena mengenai besarnya bagian yang diterima oleh pemilik faktor produksi (petani ikan, buruh tani, dan pengusaha sarana produksi), dengan menghimpun fakta, tanpa menguji hipotesis. Analisis kuantitatif dilakukan untuk menghitung besarnya pendapatan usahatani ikan nila.

\section{Analisis Pendapatan dan Distribusi Pendapatan dari Pemilik Faktor Produksi}

Untuk menghitung besarnya pendapatan usaha pembesaran ikan nila, dihitung dengan langkah-langkah perhitungan menurut Soekartawi (1995). Menurut Suratiyah (2015), langkah-langkah tersebut yaitu menghitung penerimaan, biaya, dan pendapatan. Secara matematis besarnya pendapatan dirumuskan :

$$
\mathrm{I}=\mathrm{TR}-\mathrm{TC}
$$

dimana I adalah pendapatan, TR adalah penerimaan, dan TC merupakan biaya total.

Untuk mengetahui distribusi pendapatan pemilik faktor produksi (petani ikan, buruh tani, dan pengusaha sarana produksi), dengan menghitung bagian yang diterima oleh masing-masing pemilik faktor produksi. Menurut Jatileksono (1981) bahwa besarnya bagian yang diterima setiap pemilik faktor produksi dapat dirumuskan :

BagianPemilikFaktorProduksi $=\frac{\text { PembayaranfaktorproduksiA }}{\text { PendapatanKotor }}$

Menurut Todaro dan Smith (2004) bahwa distribusi fungsional atau distribusi kepemilikan faktor produksi, dengan indikator berfokus pada besarnya bagian yang diterima oleh masing-masing pemilik faktor produksi

\section{HASIL DAN PEMBAHASAN}

\section{Karakteristik Petani Ikan}

Hasil penelitian menunjukkan bahwa umur petani ikan nila berkisar antara 24 - 61 tahun dengan rata-rata umur sebesar 42,82 tahun. Hal ini menunjukkan bahwa umur petani ikan nila berada pada golongan usia produktif yang mana pada usia tersebut dapat mendukung usaha petani ikan, sehingga dapat bekerja dan berpikir secara optimal. Mubyarto (1989), 
mengatakan bahwa petani yang berada pada usia produktif akan memberikan hasil yang maksimal dibanding dengan usia yang tidak produktif, usia produktif berkisar antara 15 - 64 tahun.

Tingkat pendidikan formal seseorang merupakan faktor penunjang keberhasilan dalam mengembangkan usaha, karena pemdidikan formal akan menentukan kemampuan seseorang dalam menyerap informasi dan inovasi (Asmira, 2011). Hasil penelitian menunjukkan tingkat pendidikan petani ikan nila berada pada kisaran 5 - 17 tahun, dengan rata-rata tingkat pendidikan selama 10 tahun. Hal ini mengindikasikan tingkat pendidikan petani ikan nila masih berada pada keadaan yang cukup yaitu tingkat SLTP. Dengan tingkat pendididkan cukup dan diimbangi dengan pengalaman usahatani ikan selama 11 tahun akan dapat membantu petani ikan dalam pengambilan keputusan dan cenderung belajar dari pengalaman sehingga petani ikan nila memiliki gambaran tentang apa yang akan dilakukan dalam peningkatan produksi pada masa yang akan datang.

Jumlah tanggungan keluarga adalah semua orang yang tinggal bersama petani ikan atau tidak tinggal bersama tetapi hidupnya masih dibiayai oleh petani tersebut (Asri, 2012). Data penelitian menunjukkan jumlah tanggungan keluarga petani ikan nila berada pada kisaran 3- 5 jiwa atau dengan persentase sebesar 83,3 persen. Dengan jumlah tanggungan keluarga yang cukup banyak akan mempengaruhi pengeluaran atau kebutuhan konsumsi keluarga petani ikan nila. Sehingga hal ini akan mendorong atau memotivasi petani ikan nila yang kuat untuk mengelola usaha budidaya ikan dengan sebaik-baiknya guna memenuhi kebutuhan keluarganya.

Dalam kegiatan usaha budidaya ikan nila luas kolam menjadi faktor penting, karena luas atau sempitnya kolam akan mempengaruhi jumlah produksi yang diperoleh. Rata-rata luas kolam yang dimiliki oleh petani ikan nila sebesar $250 \mathrm{~m}^{2}$, dengan persentase sebesar 79,6 persen. Hal ini mengindikasikan bahwa luas kolam yang dimiliki oleh petani ikan masih tergolong sempit. Sempitnya luas kolam di daerah penelitian ini lebih disebabkan oleh keterbatasan modal dan akses memperoleh informasi sumber modal bagi petani ikan.

\section{Biaya Usaha Budidaya Ikan Nila}

Biaya yang dikeluarkan dalam usaha budidaya ikan nila terdiri dari biaya tetap dan biaya variabel. Mulyadi (2007) mengatakan biaya tetap adalah biaya yang jumlah totalnya tetap dalam volume kegiatan produksi dan waktu tertentu, sedangkan biaya variabel merupakan biaya yang dalam jumlah totalnya akan berubah sebanding dengan perubahan volume kegiatan produksi. 


\section{Biaya Tetap}

Biaya tetap pada usaha budidaya ikan nila di daerah penelitian terdiri dari: biaya penyusutan alat, penyusutan kolam, dan biaya pajak. Gambaran mengenai rata-rata biaya tetap pada usaha budidaya ikan nila dapat dilihat pada Tabel 1.

Tabel 1. Rata-rata biaya tetap pada usaha budidaya ikan nila Kecamatan Seginim

\begin{tabular}{clcc}
\hline No & \multicolumn{1}{c}{ Uraian } & Rata-rata $(\mathrm{Rp} / \mathrm{UT} / \mathrm{MT})$ & Rata-rata $\left(\mathrm{Rp} / \mathrm{m}^{2}\right)$ \\
\hline 1 & Penyusutan alat & $72.180,52$ & 329,32 \\
2 & Penyusutan kolam & $611.561,40$ & $2.656,45$ \\
3 & Pajak & $3.217,92$ & 13,31 \\
\hline \multicolumn{2}{l}{ Jumlah } & $686.959,84$ & $2.999,08$ \\
\hline
\end{tabular}

Sumber : Data primer diolah, 2013.

Biaya penyusutan alat dan kolam dihitung selama 4 bulan (satu musim tebar). Dasar perhitungan harga awal dikurangi harga akhir dan dibagi umur ekonomis, dengan demikian besar kecilnya biaya penyusutan yang harus dikeluarkan oleh petani ikan sangat bergantung pada besar kecilnya nilai ketiga komponen tersebut. Hasil perhitungan diperoleh rata-rata biaya penyusutan alat sebesar Rp 72.180,52/UT/MT dan rata-rata biaya penyusutan kolam sebesar Rp $611.561,40 / \mathrm{UT} / \mathrm{MT}$. Untuk biaya penyusutan kolam lebih besar dibandingkan dengan biaya penyusutan alat, hal ini disebabkan tingginya nilai awal dari bangunan kolam.

Petani ikan nila mengeluarkan biaya pajak lahan untuk kolam, dasar perhitungan biaya pajak adalah luas kolam dibagi dengan luas lahan per hektar dikalikan besarnya pajak lahan per hektar per tahun. Hasil penelitian menunjukkan besarnya pajak lahan kolam yang dikeluarkan oleh petani ikan sebesar Rp 3.217,92/UT/MT, nilai pajak kolam relatif kecil. Hal ini karena besaran pajak lahan per hektar tidak terlalu besar.

\section{Biaya Variabel}

Biaya variabel pada usaha budidaya ikan nila di daerah penelitian adalah biaya input (bibit, pakan) dan biaya tenaga kerja. Rata-rata biaya variabel usaha budidaya ikan nila di kecamatan Seginim dapat dilihat pada Tabel 2

Biaya variabel adalah biaya yang dikeluarkan oleh petani ikan nila setiap periode 4 bulan/MT atau selama kegiatan usaha budidaya ikan berlangsung. Hasil penelitian didapat biaya variabel yang paling besar adalah biaya pakan (5 jenis pakan) yaitu sebesat Rp 52.182.195,18/UT/MT. Hal ini mengindikasikan bahwa pakan ikan merupakan faktor produksi yang sangat penting, karena tinggi rendahnya produksi ikan nila akan tergantung ketersediaan dan kecukupan pakan. Kemudian biaya variabel besar urutan kedua adalah biaya 
bibit yaitu sebesar Rp 33.783.333,33/UT/MT, tingginya biaya bibit ini disebabkan biaya bibit ikan nila yang cukup tinggi yakni sebesar Rp 18.000/kg. Biaya variabel tenaga kerja sebesar Rp 7.347.222,22/UT/MT, biaya tenaga kerja relatif rendah hal ini dikarenakan masih murahnya upah tenaga kerja di daerah penelitian yaitu sebesar Rp 50.000/HOK.

Tabel 2. Rata-rata biaya variabel usaha budidaya ikan nila

\begin{tabular}{llcccc}
\hline No & Uraian & $\begin{array}{c}\text { Jumlah } \\
(\mathrm{kg})\end{array}$ & $\begin{array}{c}\text { Harga } \\
(\mathrm{Rp} / \mathrm{kg})\end{array}$ & $\begin{array}{c}\text { Rata-rata } \\
(\mathrm{Rp} / \mathrm{UT} / \mathrm{MT})\end{array}$ & $\begin{array}{c}\text { Rata-rata } \\
\left(\mathrm{Rp} / \mathrm{m}^{2}\right)\end{array}$ \\
\hline 1 & Bibit & $1.876,85$ & 18.000 & $33.783 .333,33$ & $149.383,98$ \\
2 & Pakan & & & & \\
& a. T78-2A & $2.103,70$ & 6.500 & $13.674 .074,07$ & \\
& b. $781 \mathrm{~N}$ & $1.944,44$ & 7.500 & $14.583 .333,33$ & \\
& c. 788 & $1.625,93$ & 7.000 & $11.381 .481,48$ & \\
& d. 799 & $1.074,07$ & 7.000 & $7.518 .518,52$ & \\
& e. SPM4-B & 670,37 & 7.500 & $5.027 .777,78$ & $225.501,50$ \\
3 & Tenaga kerja & & & $7.347 .222,22$ & $37.195,50$ \\
\hline & & & & $93.315 .740,74$ & \\
\hline
\end{tabular}

Sumber : Data primer diolah, 2013

\section{Penerimaan dan Pendapatan Usaha Budidaya Ikan Nila}

Rata-rata produksi, penerimaan, dan pendapatan usaha budidaya ikan nila di Kecamatan Seginim dapat dilihat pada Tabel 3.

Tabel 3. Rata-rata Produksi, penerimaan dan pendapatan Usaha Budidaya Ikan Nila di Kecamatan Seginim

\begin{tabular}{llr}
\hline No & \multicolumn{1}{c}{ Uraian } & Rata-Rata $(\mathrm{UT} / \mathrm{MT})$ \\
\hline 1 & Produksi $(\mathrm{kg})$ & $6.079,87$ \\
2 & Harga (Rp/kg) & $19.000,00$ \\
3 & Penerimaan (Rp) & $115.517 .537,00$ \\
4 & Total biaya (Rp) & $93.312 .750,73$ \\
5 & Pendapatan (Rp) & $22.204 .786,27$ \\
\hline
\end{tabular}

Sumber : Data Primer diolah, 2013

Berdasarkan Tabel 3, rata-rata pendapatan petani ikan nila sebesar Rp 22.204.786,27/UT/MT. Pendapatan petani ikan nila tersebut pada saat penelitian masih tergolong rendah, hal ini disebabkan harga jual ikan nila relatif rendah yaitu Rp 19.000/kg. Menurut pengakuan petani ikan nila (Firman), biasanya harga yang diterima sebesar Rp 21.000/kg. Hasil penelitian Rahayu (2011) mengenai pendapatan ikan nila di Kabupaten Klaten diperoleh pendapatan sebesar Rp2.387.170,47/257m²/bulan.

164 | Sriyoto, Reswita dan Hadianto, Analisis Distribusi Pendapatan Usaha ... 


\section{Distribusi Pendapatan Ditinjau dari Pemilik Faktor Produksi}

Distribusi pendapatan dapat diartikan sebagai pembagian atau pemerataan hasil yang diperoleh dari suatu kegiatan usaha (Ratag, 2001). Para ekonom pada umumnya membedakan dua ukuran pokok distribusi pendapatan yaitu besar atau kecilnya bagian pendapatan yang diterima masing-masing orang, dan distribusi kepemilikan faktor-faktor produksi, yang indikatornya berfokus pada bagian pendapatan diterima oleh masing-masing pemilik faktor produksi (petani ikan, buruh tani, dan pengusaha sarana produksi). Gambaran mengenai besarnya bagian yang diterima oleh petani ikan, buruh tani, pengusaha sarana produksi (pakan dan bibit), serta pendapatan kotor budidaya ikan nila dapat disajikan pada Tabel 4.

Tabel 4. Bagian yang diterima oleh pemilik faktor produksi pada budidaya ikan nila di Kecamatan Seginim

\begin{tabular}{clcc}
\hline No & \multicolumn{1}{c}{ Uraian } & $\begin{array}{c}\text { Bagian yang diterima pemilik } \\
\text { faktor produksi (Rp) }\end{array}$ & Persentase (\%) \\
\hline 1 & Petani Ikan & $22.204 .786,27$ & 19,22 \\
2 & Buruh Tani & $7.347 .222,22$ & 6,36 \\
3 & Pengusaha bibit & $33.783 .333,33$ & 29,25 \\
4 & Pengusaha pakan & $52.182 .195,18$ & 45,17 \\
\hline Penerimaan kotor & $115.517 .537,00$ & 100,00 \\
\hline
\end{tabular}

Sumber: Data primer diolah, 2013

Dari Tabel 4 diketahui besarnya bagian yang diterima pengusaha pakan ikan sebesar Rp52.182.195,18 atau sebesar 45,17 persen. Hal ini mengindikasikan bahwa di dalam usaha budidaya ikan nila faktor produksi (pakan ikan) merupakan faktor yang penting dalam kaitannya dengan produksi. Kemudian besarnya bagian yang diterima pengusaha bibit ikan sebesar Rp33.783.333,33 atau sebesar 29,25 persen. Pada umumnya pengusaha sarana produksi di bidang perikanan akan memperoleh bagian pendapatan yang cukup besar. Besarnya bagian yang diterima oleh petani ikan sebesar Rp22.204.786,27 atau sebesar 19,22 persen, sedangkan besarnya bagian yang diterima buruh tani sebesar Rp7.347.222,22 atau sebesar 6,36 persen. Hal ini wajar karena buruh tani hanya mendapatkan upah buruh yang relatif rendah di bidang pertanian pada umumnya, sehingga besarnya bagian yang diterima buruh tani relatif kecil.

\section{SIMPULAN DAN SARAN}

\section{Simpulan}

1. Pendapatan petani ikan nila sebesar Rp22.204.786,27/UT/MT. 
2. Besarnya bagian yang diterima pengusaha pakan ikan sebesar 45,17 persen; pengusaha bibit ikan sebesar 29,25 persen; petani ikan sebesar 19,22 persen; dan buruh tani sebesar 6,36 persen.

\section{Saran}

1. Dalam upaya peningkatan efisiensi usaha, petani ikan perlu melakukan efisiensi biaya terutama biaya pakan dengan mengkombinasikan pakan buatan dan pakan alami yang harganya cukup murah.

2. Pemerintah diharapkan dapat meningkatkan kegiatan penyuluhan bagi petani ikan nila terkait dengan teknologi budidaya agar tidak banyak ikan yang mati. Di samping itu pemerintah hendaknya dapat memberikan kebijakan harga bibit ikan yang cukup mahal, sehingga penerimaan petani ikan meningkat.

\section{DAFTAR PUSTAKA}

Asmira, Y. 2011. Analisis faktor-Faktor Produksi dan Pendapatan Usahatani Nila Sistem Kolam Air Deras di Desa Tanah Periuk II, Kecamatan Muara Belili, Kabupaten Musi Rawas, Provinsi Sumatera Selatan. Skripsi Sosial Ekonomi Pertanian. UNIB. Bengkulu. (tidak dipublikasikan).

Asri, R.A. 2012. Analisis Pendapatan dan Efisisensi Usaha Budidaya Ikan Nila Merah dan Ikan Nila Biasa pada Kolam Air Tenang di Desa Tegalrejo, Kecamatan Tugumulyo, Kabipaten Musi Rawas, Provinsi Sumatera Selatan. Skripsi Sosial Ekonomi Pertanian. UNIB. Bengkulu. (tidak dipublikasikan).

Jatileksono, T. 1981. Impact of Tubewell Irrigation Projects on Productivity, And Income Distribution in Kediri District East Java. Thesis. University of the Phillippine at Las Banos.

Mubyarto. 1989. Ekonomi Pertanian. Edisi Ke-tiga, LP3ES, Jakarta.

Mulyadi. 2007. Akuntansi Biaya, Edisi 5. Graha Ilmu, Yogyakarta.

Rahayu, W. 2011. Analisis Pendapatan Usaha Pembesaran Ikan Nila Merah pada Kolam Air Deras di Kecamatan Polanharjo, Kabupaten Klaten. Jurnal IlmuIlmu Pertanian 7(1): --. Juli 2011.

Ratag. 2001. Distribusi pendapatan Petani Tomat di Desa Ampreng kecamatan Langowan Barat. Skripsi Pertanian UNSRAT, Manado.

Soekartawi. 1995. Analisis Usahatani. UI Press, Jakarta.

Suratiyah, K. 2015. Ilmu Usahatani Edisi Revisi. Penebar Swadaya, Jakarta.

Todaro, M.P dan Smith, S.C. 2004. Pembangunan Ekonomi di Dunia Ketiga. Edisi ke 8. Erlangga, Jakarta. 